\title{
Cultivation of Shiitake Mushroom (Lentinus edodes) on Coffee Husk at Dilla University, Ethiopia
}

\author{
Fekadu Alemu \\ Department of Biology, College of Natural and Computational Sciences, Dilla University, Dilla, Ethiopia \\ Email address: \\ fekealex@gmail.com \\ To cite this article: \\ Fekadu Alemu. Cultivation of Shiitake Mushroom (Lentinus edodes) on Coffee Husk at Dilla University, Ethiopia. Journal of Food and \\ Nutrition Sciences. Vol. 3, No. 2, 2015, pp. 64-70. doi: 10.11648/j.jfns.20150302.16
}

\begin{abstract}
Mushroom cultivation is one of the efficient ways by which residues can be recycled and also improve food supply with high food quality to the humans. Cultivation of shiitake mushroom has increased tremendously throughout the world because of its abilities to grow at a wide range of temperature and utilized various agro-based residues as well as its medicinal value. Therefore the present study was designed to primarily assessing the cultivation of Lentinus edodes on abundantly available solid wastes (Coffee husk) for conversions in to foods which otherwise is left for natural degradation and also provide necessary information for their further utilization. As result revealed, Lentinus edodes was cultivated on coffee husk through yielding much of fruit body. Therefore, Lentinus edodes is one of the best mushroom that can be convert this solid reside in to therapeutic agent contain foods.
\end{abstract}

Keywords: Coffee Husk, Fruit Body, Lentinus edodes, Mushroom Cultivation, Spawn

\section{Introduction}

Mushrooms are the fruiting bodies of certain types of fungi, many of which can play highly beneficial roles in forest ecosystems. Many of these fungi have unique abilities to break down wood, leaves, and other organic matter and recycle nutrients back into the system. Pleurotus species are popular and widely cultivated throughout the world mostly in Asia and Europe owing to their simple and low cost production technology and higher biological efficiency (Mane et al., 2007). Pleurotus species are efficient lignin degraders which can grow on wide variety of agricultural wastes with broad adaptability to varied agro climatic conditions (Jandaik and Goyal, 1995). Edible mushrooms provide high quality of protein that can be produced with greater biological efficiency than animal protein, rich in fiber, minerals and vitamins and have low fat content, with high proportion of polyunsaturated fatty acids relative to total content of fatty acids (Marshall and Nair, 2009).

In general, the gross composition of mushrooms is water $(90 \%)$, protein $(2-40 \%)$, fat $(2-8 \%)$, carbohydrates $(1-55 \%)$, fiber (3-32\%), and ash (8-10\%) (Firenzuoli et al., 2008). Commonly cultivated mushrooms of genus Pleurotus are interesting because of its $\beta$-glucans demonstrating great immunomodulation, antioxidant, antiinflammatory and analgesic properties (Bobek and Galbavy, 2001; Smiderle et al., 2008). High fiber content, proteins, microelements, and lower caloric content are found almost ideal for a nutrition program aimed to the prevention of hypercholesterolemia and cardiovascular diseases (Daba et al., 2008). Similarly, the use of mushroom for anticancer activities (Mizuno, 1999; Gue et al., 2006), reduction of total blood cholesterol and lipoprotein cholesterol and antioxidant activities, the regulation of blood lipid levels and reduction of blood glucose levels (Gue et al., 2006) have been reported. Studies also revealed that the United Nations Food and Agriculture Organization (FAO) strongly advices the consumption of mushroom due to their high nutritional and medicinal values (Marshal and Nair, 2009).

Coffee husks are the major solid residues from the handling and processing of coffee, since for every kilo grams of coffee beans produced, approximately one kilo grams of husks are generated. Proposed alternative uses for coffee husks include employing this solid residue as a supplement for animal feed, direct use as fuel and fermentation for the production of a diversity of products (enzymes, citric acid and flavouring substances), use as a substrate for growth of mushrooms and use as adsorbents. Such residue consists mainly of the pulp and hull of the coffee fruit; it presents a high concentration of carbohydrates and thus can be viewed as a potential raw material for bio-ethanol production (Franca and Oliveira, 2009). 
Chang (1999) reported Pleurotus spp. as one of the valuable and edible mushrooms. It occupies the third place in the world's production of edible mushrooms, after Agaricus bisporus and Lentinula edodes, however, in recent years; it is reported to be the second most important mushrooms in production in the world of which $25 \%$ of the total world production of cultivated mushrooms are Pleurotus. Pleurotus as a class of edible mushroom has the capacity to convert nutritionally valueless substances into high protein food and are reputed to have a high saprophytic ability and to grow on a variety of cellulosic wastes (Yildiz et al., 2002).

Mushrooms cultivation offers benefit to market gardens when it is integrated into the existing production system by producing nutritious food at a profit, while using materials that would otherwise be considered "waste" (Beetz and Kustudia, 2004). This is because mushrooms contain many essential nutrients and they are found to solve dietary related health problems (Atikpo et al., 2008). In Ethiopia, mushroom eating is very poor (Abate, 1998). Information on nutritive value and sensory properties of edible oysters mushroom foods cultivated on Agricultural residues in Ethiopia is limited such information is important to facilitate the population of mushroom cultivation, processing, marketing and consumptions.

In most parts of Ethiopia, wild edibles form integral parts of the feeding habits of many communities (Balemie and Kibebew, 2006). However, consumption of wild edibles is more common in food insecure areas than in other areas in the country (Teklehaymanot and Giday, 2010). Mushroom cultivation is a very recent activity in Ethiopia. The first small scale mushroom farm was started in 1997 by the cultivation of the oyster (Pleurotus ostreatus) mushroom later, the button (Agarics bisporus) followed by the shiitake (Lentinula edodes) mushrooms have been introduced to the local market (Abate, 1998). Mushrooms with their flavour, texture, nutritional value, and high productivity per unit area have been identified asan excellent food source to alleviate malnutrition in developing countries (Eswaran and Ramabadran, 2000).

Small scale mushroom production represents an opportunity for farmers interested as an additional work, and is specially an option for farmers with no adequate farm lands (Beetz and Kustudia, 2004) especially in the current alarmingly increasing Ethiopian population. The consumption of mushroom can make a valuable addition to the often unbalanced diets of people in developing countries and they are considered to provide a fair substitute for meat with at least a comparable nutritional value to many vegetables (Marshall and Nair, 2009). According to Tuno (2001), mushroom is a seasonal organism characterized by the alternation of rainy season, from May/June to September /October and a dry season for the rest of the year mostly grows in the climate of Ethiopian plateau, particularly, in the south-western part of the country.

The mushroom is not a traditional crop in Ethiopia or in Africa in general and the low level of research and training in mushroom cultivation is the main problem hampering the development of mushroom production. Regional training courses tailored to mushroom growers, spawn technicians and agricultural extension workers are planned. Appropriate books and practical manuals are also urgently needed. Mushroom cultivation requires expertise in the techniques of spawn making, substrate preparation, composting, and pest control, harvesting and packing. Without this knowledge base, mushroom cultivation would fail (Abate, 1995). With Ethiopian growing population coupled with increase in demand for food, cultivation of mushroom can be one of the alternatives to address nutritional security in relatively small farm space and cheap substrates such as agricultural wastes which can also be recycled, thereby leading to conservation of natural resources (Abate, 1995).

Mushroom cultivation is one of the efficient ways by which residues can be recycled. Coffee husk in Ethiopia particularly in Dilla town and surrounding areas are removing as solid waste. Cultivation of Lentinus edodes mushroom on this substrate has a good acceptance from the consumer and also a good opportunity for small producers to embark in an enterprise. Even when the mushroom is well known only a small fraction of the production is cultivated, it is very important to do more research to develop a system that can adapt completely to the rural producers and urban of Ethiopians. Therefore the present study will be designed to primarily assessing the cultivation of Lentinus edodes on some common and abundantly available solid wastes (Coffee husk) for conversions in foods which otherwise is left for natural degradation and also provide necessary information for their further utilization. Additionally to create awareness about importance of mushroom as well as their mushroom consumption habit will help for proper management of this natural resource in addition to serving as primary information for further research.

\section{Material and Methods}

\subsection{Pure Culture Collection and Maintain}

Shiitake mushroom was obtained from Mycology Laboratory, Department of Biology from Addis Ababa University. The pure culture of Shiitake mushroom was inoculated onto Malt extract agar. The pure culture was maintained on Malt extract agar slants at $-4^{0} \mathrm{C}$ for one month, then sub-culturing subsequently after one month transferred (inoculated) onto fresh slant of Malt extract agar.

\subsection{Substrate Collection}

Coffee husk used as substrate for composting was obtained around Dilla town October -2014 April (figure 1). Other nutrient supplement such as wheat bran and $\mathrm{pH}$ adjustment of Wood ash was obtained from the Dilla town. Beside this Cow dung and Chicken manure was obtained from Allege Research centre. 


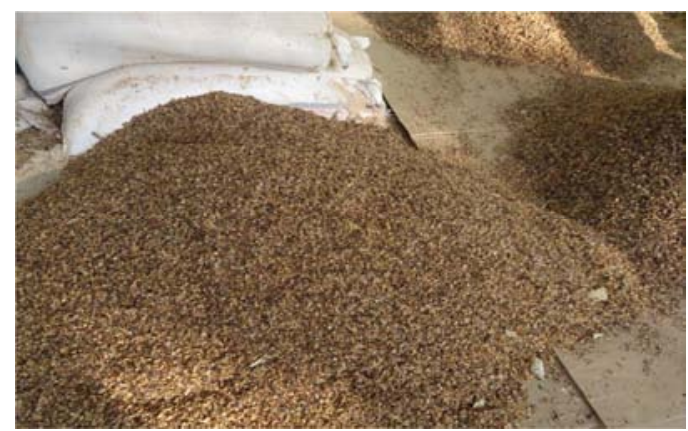

Figure 1. Coffee husk.

\subsection{Compost Preparation}

The compost was prepared by outdoor single-phase solidwaste fermentation (Nair and Price, 1991). In order to prepare, aerobic composted substrate, about $80 \%$ of coffee husk was mixing with Wood ash, Wheat bran, Cow dung and
Chicken manure, then the water was added until moisture content was between $40-60 \%$ as indicated figure 2 . This is usually being determined by the 'rule of thumb' method (Buswell, 1984). Then supplement with $20 \%$ of three different supplements on $80 \%$ of coffee husk as follows:-

Substrate A. 10\% Chicken manure, $8 \%$ Wheat bran and $2 \%$ wood ash

Substrate B. 10\% Cow dung, $8 \%$ Wheat bran and 2\% wood ash

Substrate B. 18\% Wheat bran and $2 \%$ wood ash

Substrate C. 18\% Cow dung and 2\% wood ash

Substrate D. 18\% Chicken manure and 2\% wood ash on dry weight basis with some Modification of (Dawit, 1998). The substrates were then added into hole of about $1.5 \mathrm{~m}$ wide, $1.5 \mathrm{~m}$ high and $1.5 \mathrm{~m}$ long which was under shadow area at Dilla University. This was covered with banana leaves and left for 2 weeks with turning and restacking every 3-4 days to produce homogenous compost.

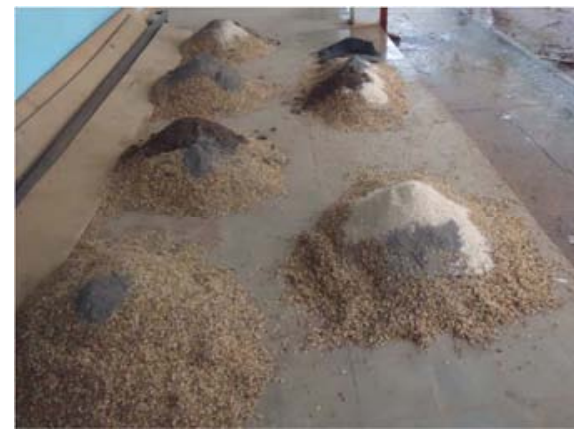

A

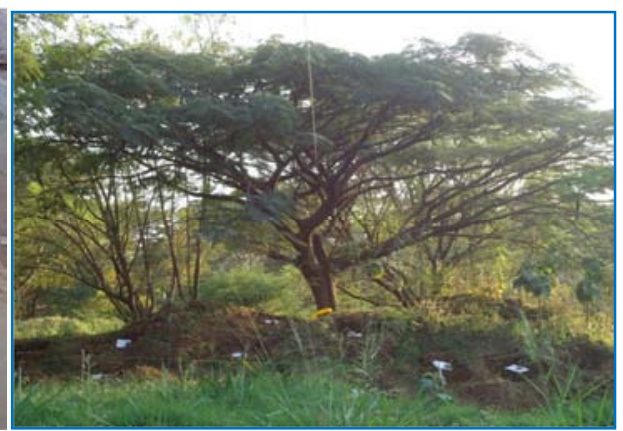

B

Figure 2. A, coffee husk contain supplement ingredients; B, Composting area.

\subsection{Spawn Production}

Spawn is the vigorous mycelia growth of a single fungus on a chosen substrate material (liquid media, grains, saw dust substrate, wooden sticks (Jiskani, 2000). Sorghum was used for mother spawn. About $20 \mathrm{~kg}$ of sorghum was washed and dead floating removed then soaked overnight in $15 \mathrm{~L}$ water and rinsed three times in distilled water. The excess water was drained off and $20 \%$ wheat bran, $12 \%$ gypsum $\left(\mathrm{CaSo}_{4}\right.$. $\left.2 \mathrm{H}_{2} \mathrm{O}\right)$, and $3 \%$ limes $(\mathrm{CaCO} 3)$ were added (Figure 3$)$. The ingredients were thoroughly mixed; moisture was maintained at the level of $55 \%$, and distributed equally in to $500 \mathrm{ml}$ glass bottle at the rate $370.66 \mathrm{~g}$ seed per bottles and autoclaved for $121^{\circ} \mathrm{C}$ to 1 hour. After cooling, each bottle was inoculated with 7 days old culture which grown on Malt extract agar and incubated for 25 days at $25^{\circ} \mathrm{C}$ until the substrate fully colonized; at ten days interval mycelia invasion and contamination were recorded.

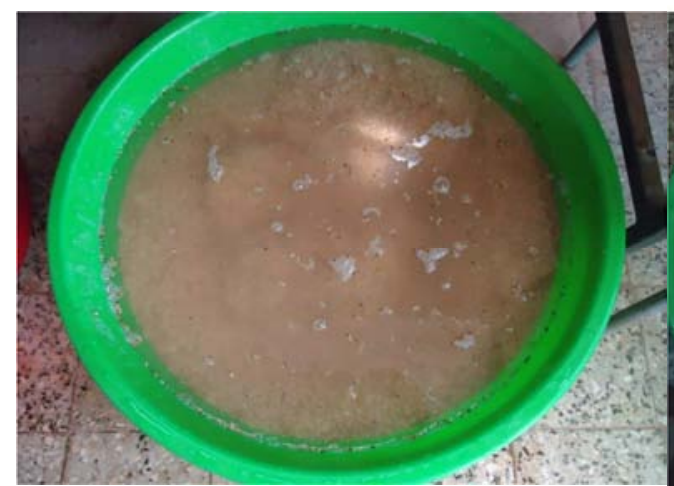

A

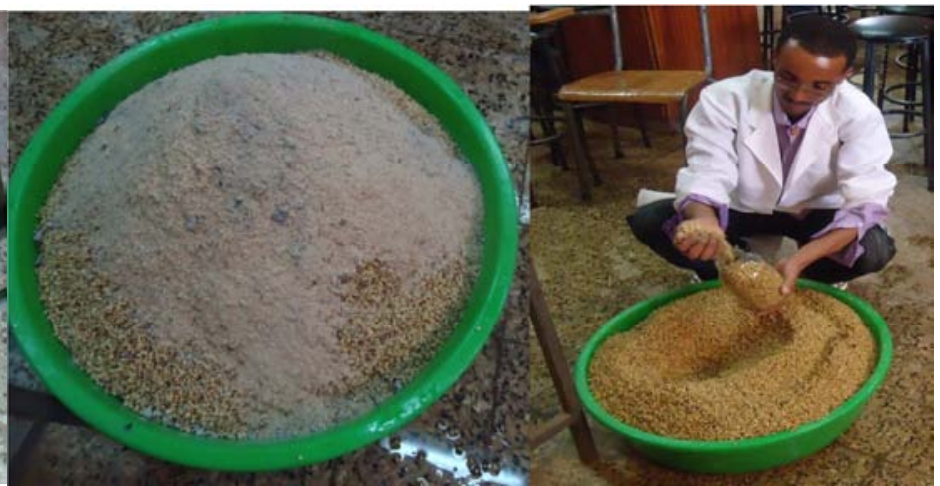

B

C

Figure 3. A, soaked in tap water overnight; B, supplement of wheat bran and pH adjustment; $C$, addition of formulated sorghum into glass bottle made ready for sterilization. 


\subsection{Sterilization of Substrates and Cultivation of Mushrooms}

After two weeks of composting, these substrates were distributed equally into plastic bags of $40 \times 60 \mathrm{~cm}$ size at the rate of $3.5 \mathrm{~kg}$ substrate in triplicates and sterilized for three hours in barrel by fire. After cooling; they were inoculated with the spawn (one glass bottle per bag) and mixed thoroughly to facilitate rapid and uniform mycelia growth. The mouth of the bags was tied using a cotton plug and thread and holes were made over the polythene bags for aeration. Then, they were incubated in the dark at $27^{\circ} \mathrm{C}$ and mycelia development in the bag was observed and noted within 5 days.

\subsection{Data Analysis}

The data of actively mycelium growth during spawn making and formation of full morphology of shiitake mushroom and fruiting body were observed during cultivating on substrate.

\section{Result and Discussion}

Shiitake mushroom was cultured on malt extract agar for 7 days at $28^{\circ} \mathrm{C}$ and mycelium covered the medium as indicated in Figure 4. During mycelium growth, there is a circular pattern of mycelium growth observed on plates. Cultivated mushroom are generally saprophytes, utilizing substrate as primary or secondary decomposers (Stott and Caroline, 2004). Habitats in which mushrooms are found include grassy meadows, deciduous hardwoods, woodlands where they grow up lingo cellulosic, (hemi) cellulose substrates, such as straw, hard, and soft woods of the temperate as well as tropical region (Chang and Miles, 1997). Their relative adaptability to various substrate species and forms, (stumps, logs, wood particles, leaf litter) and their preferences with respect to the microbiological condition of their substrates (Bruhn, 1998) was conducted.

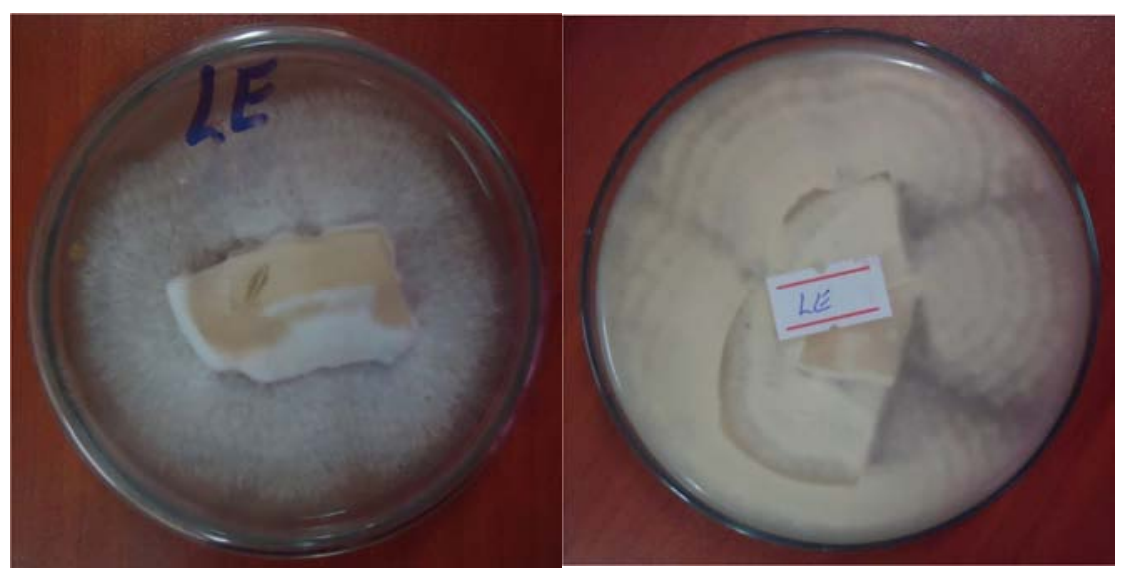

A

B

Figure 4. Shiitake mushroom mycelium grown on malt extract agar: A, Front observation of mycelium on plate; B, back observation of mycelium on plate.

\subsection{Spawn Production}

Sorghum is important cereals for spawn production of mushroom species. Sorghum based spawn took 25 days to colonize the substrate completely figure 5. The moisture content of the sterile moist sorghum $(55-60 \%)$ was found to be suitable.

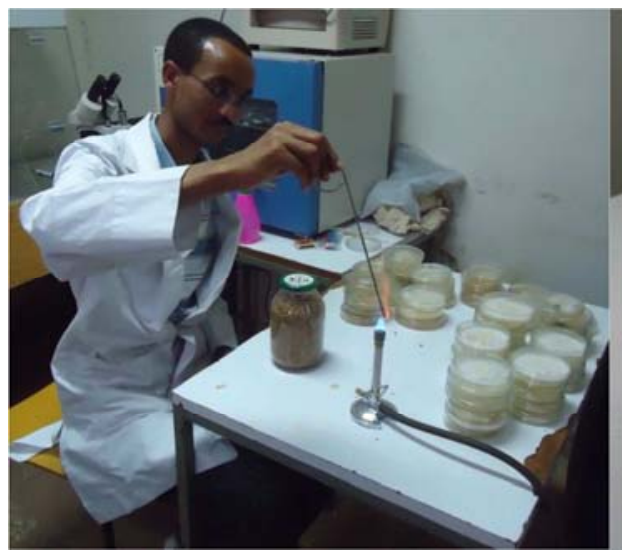

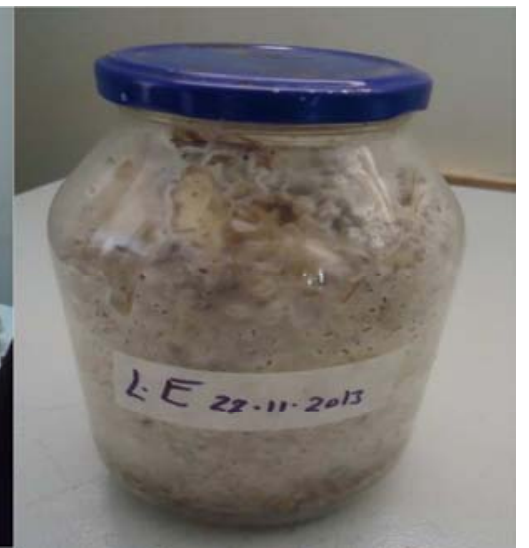

Figure 5. Spawn preparation on sorghum: A, inoculation of old culture (7 days) shiitake mushroom on the sorghum; B, fully colonized sorghum by shiitake mushroom mycelium after 25 days. 


\subsection{Substrate Sterilization and Spawn Inoculation}

The substrate was sterilized by in boiling water for three hours. Mycelium running rate on the substrates was observed after 7 days inoculation of spawn (figure 6). This is occurring when the humidity and cultivation room maintain at high humidity and room at dark. Edible mushrooms are recommended by the FAO as food, contributing to the protein nutrition of developing countries dependent largely on cereals with it became a new and alternative demand for poultry and animal protein in fresh mushrooms. In general mushrooms are highly nutritious, their taste and delightful aroma makes them one of the delicious preferred foods in restaurants throughout the world (Chang and Mshignei, 2000). On the other hand, spent mushroom substrate has been as animal feed, since its degradation by the mushroom can improve its nutritional quality and digestibility (Suzuki et al., 1994).

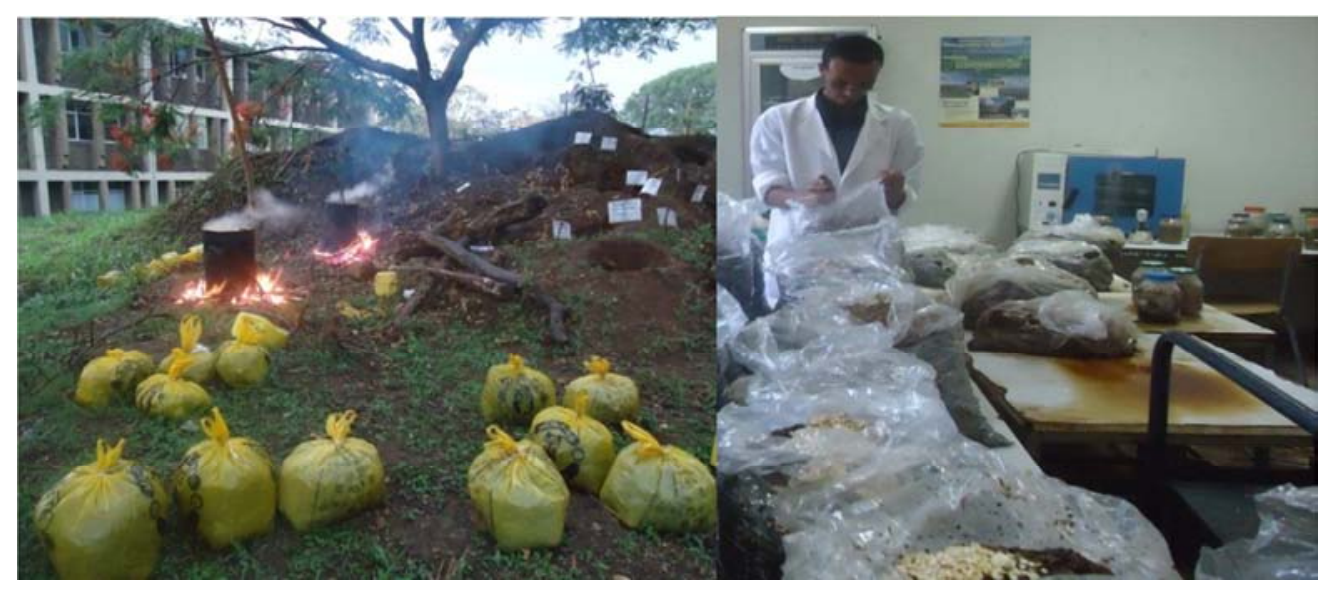

A

B

Figure 6. Sterilization and inoculation spawn: A, sterilization of substrate; B, inoculation of shiitake mushroom spawn on corn bran substrate.

\subsection{Fruiting Body Production}

Fruiting body is the edible part of mushroom (Lentinus edodes). The fruiting body was observed after 20 day of spawn inoculated later. The fruiting body grown double or more than two fruit body together as in shown in figure 7. The harvesting date also varied depending upon types of substrate. Mushroom matured generally 48 hours after appearing (forming) the primordia. The food for human beings comes from three different sources, i.e. land, water, and microbes. Among microbes used as human food, the fungi comprise the largest and the most important group containing edible mushrooms (Singh, 2008). Healthy nutrition and diet are gaining importance, not only in the everyday life of human beings, but also in the treatment of chronic diseases. Medical practitioners of worldwide are recognizing that mushrooms are medicinal foods rich in nutrition (Stamets, 2005). The high nutritional value of mushrooms is due to the presence of 8 essential amino-acids, polyunsaturated fatty acids (linoleic and arachidonic acids) and reduced quantities of saturated fatty acids (Fortes et al., 2006). Fauzia showed that mushrooms have higher nutritional values than fish or beef (Fauzia et al., 2003). Matila also suggested that a diet rich in mushrooms provides all the essential amino acids usually available in fruits and vegetables (Matila et al., 2002).

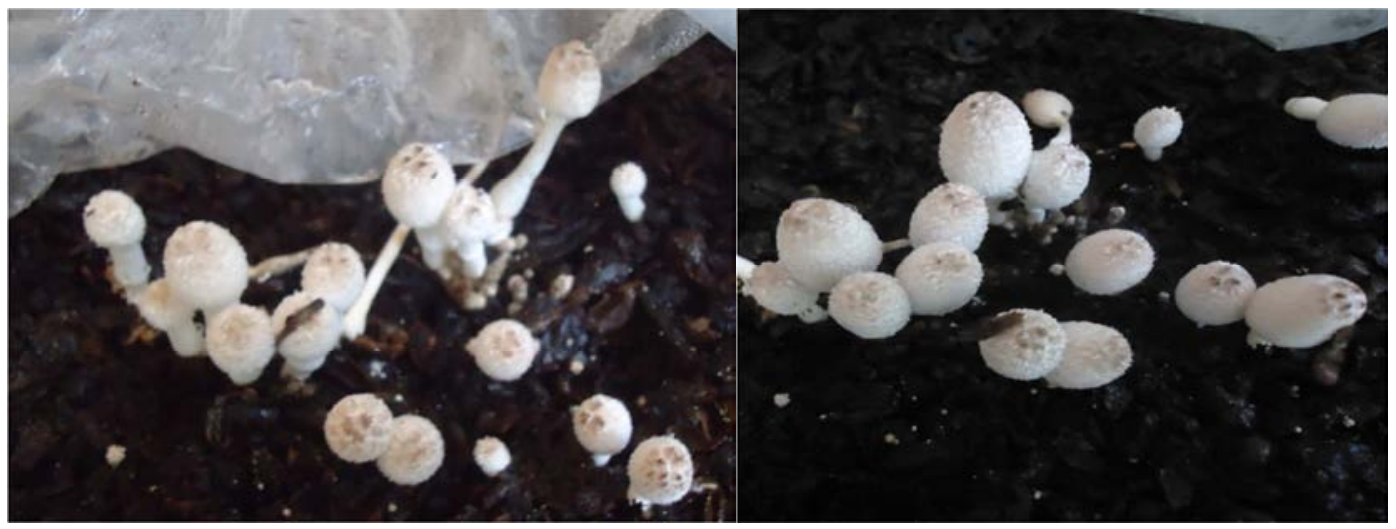



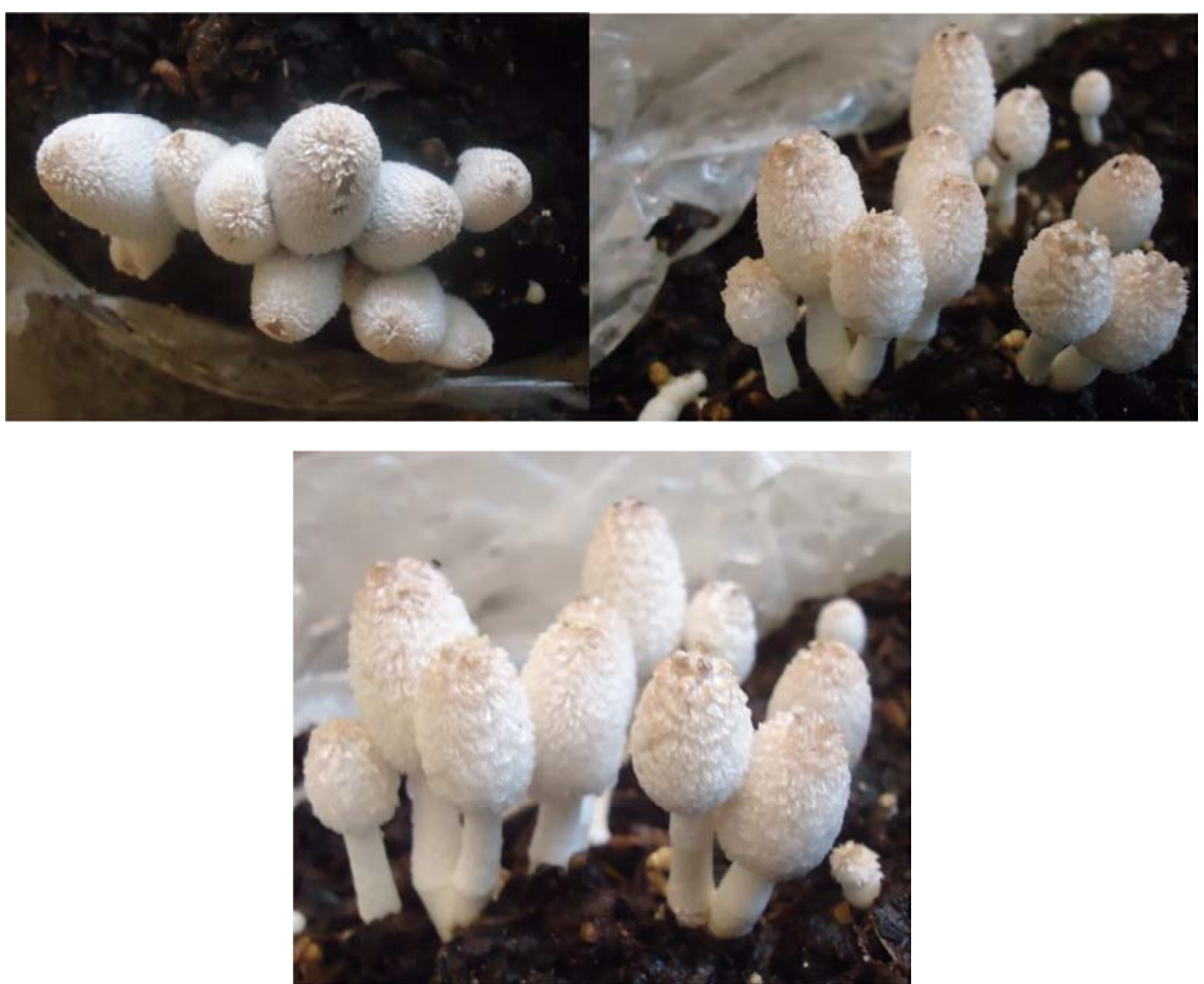

Figure 7. Fruit body grown on the coffee husk, the fruit body was grown double by forming fork like structure.

\section{Conclusion}

Mushroom cultivation is the wisdom by natural try to cultivate on disposal substrates that are not consumed by humans. Shiitake mushroom is one of the mushroom that can be convert this waste in to therapeutic agent contain foods. Commercial production of Shiitake mushroom is largely profitable on this easily availability and utilized cheap byproducts waste materials of agricultural wastes.

\section{Acknowledgements}

The authors are greatly acknowledged the Departments of Biology, College of Natural, and Computational Sciences of Dilla University for the kind assistance in providing the laboratory facilities and all the required consumables and equipment during the whole period of this research works.

\section{References}

[1] Abate D (1995). Mushrooms and Mushroom Cultivation in Ethiopia. Fifth Annual Conference of the Biological Society of Ethiopia, Addis Ababa, Ethiopia.

[2] Abate D (1998). Mushroom cultivation: A practical approach. Berhanena Selam Printing Press, Addis Ababa, Ethiopia.

[3] Atikpo M, Onokpise O, Abazinge M, Louime C, Dzomeku M,
Boateng LA (2008). Sustainable mushroom production in Africa: A case study in Ghana. Afr. J. Biotechnol. 7: 249 -253.

[4] Balemie K, Kibebew F (2006). Ethnobotanical study of wild edible plants in Derashe and Kucha Districts, South Ethiopia. J. Ethnobiol. Ethnomedicine 2: 53.

[5] Beetz A, Kustudia M (2004). Mushroom cultivation and marketing: Horticulture production guide. Nationalcenter for appropriate technology, California, USA.

[6] Bobek P, Galbavy S (2001). Effect of pleuran ( $\beta$-glucan from Pleurotus ostreatus) on the antioxidant status of the organism and on dimethylhydrazine-induced precancerous lesions in rat colon. British J. Biomedical Sci. 58: 164-168.

[7] Bruhn JN (1998). What do we still need to know about commercial production of forest grown specialty fungi?. J. Agro. Forestry 5:150-158.

[8] Buswell JA (1984). Potentials of Spent Mushroom Substrates for Bioremediation Purposes. Compost 2: 31-35.

[9] Chang ST (1999). World production of cultivated and medicinal mushrooms in 1997 with particular emphasis on Lentinula edodes (Berk.) Sing. In China. Int. J. Medicinal Mushroom 1: 291-300.

[10] Chang ST, Miles PG (1997). Mushroom biology concise basics and current Development. Singapore publication press. pp: 4-6.

[11] Chang ST, Mshignei W (2000). Ganoderm lucidum; paramount among medicinal mushrooms. J. Disco: Innovation 12: $97-101$. 
[12] Daba AS, Kabeil SS, Botros WA, El-Saadani MA (2008). Production of mushroom (Pleurotus streatus) in Egypt as source of nutritional and Medicinal food. World J. Agr. Soc. 4:630-634.

[13] Dawit, A. (1998). Mushroom Cultivation; A Practical Approach. Addis Ababa: Berhanena Selam Printing Enterprise.

[14] Eswaran A, Ramabadran R (2000). Studies on some physiological, cultural and post harvest aspects of oyster mushroom, Pleurotuseous. Tropical Agricultural Res. 12:360 -374 .

[15] Fauzia H, Majedda B, Sahana P, Zaibun N, Azad, KM (2003). Study of edible mushroom grown on Eucalyptuses camaldullensis trunk and under the soil of Albizzia procera. Pakistan. J. nutr. 2(5): 279-282.

[16] Firenzuoli F, Gori L, Lombardo G (2008).The Medicinal Mushroom Agaricus blazei Murrill: Review of Literature and Pharmaco-Toxicological Problems. eCAM. 5: 3-15.

[17] Fortes RC, Taveira VC, Rita M, Novaes CG (2006). The immunomodulator role of $\beta$-D-glucans as co-adjuvant for cancer therapy. J. Biotech. 21(2): 163-168.

[18] Franca AS, Oliveira LS (2009). Coffee processing solid wastes: current uses and future perspectives. In: Agricultural Wastes. (Columbus, F. ed.). Nova Publishers, New York.

[19] Gue SC, Woo SJ, Hyo CJ, Kwan CC, Heui YC, Tae CW, Hyun HS (2006). Macrophage activation and nitric oxide production by water soluble component of Hericium erinaceum. Int. Immunopharmacol. 6: 1363-1369.

[20] Jandaik CL, Goyal SP (1995). Farm and farming of oyster mushroom (Pleurotus $s p$ ). In: Mushroom Production Technology (Eds. Singh, R. P. and Chaube, H. S.). G.B. Pant Univ. Agril. And Tech., Pantnagar India 72-78.

[21] Jiskani MM, Wagan KH, Pathan MA, Jamro GH (2000). Spawn growth of oyster mushroom as affected by different temperatures and grain media. J. Farm Scie. 6 (10): 33-35.

[22] Mane VP, Patil SS, Syed AA, Baig MMV (2007). Bioconversion of low quality lignocellulosic agricultural waste into edible protein by Pleurotus sajorcaju (Fr.) Singer. J. Zhejiang University of Sci. 8: 745-751.
[23] Marshall E, Nair NG (2009). Make money by growing mushrooms. Food and Agriculture Organization of the United Nations, Rome.

[24] Matila P, Vaananen SP, Konko K, Aroy H, Jalava T (2002). Basic composition and amino acid contents of mushrooms cultivated in Finland. J. Agri. Food Chem. 50: 6419-6422.

[25] Nair NG, Price G (1991). A Composting process to minimize odour pollution. Mushroom Science 13: 205-206.

[26] Singh S (2008). Mushrooming enterprise protein revolution through mushroom cultivation. J. Agri. rular development 1: 15-17.

[27] Smiderle FR, Olsen LM, Carbonero ER, Baggio CH, Freitas CS, Marcon R (2008). Anti-inflammatory and analgesic properties in a rodent model of $\alpha(1-3)$, (1-6)-linked $\beta$-glucan isolated from Pleurotus pulmonarius. European J. Pharmacol. 597: 86-91.

[28] Stamets P (2005). Notes on nutritional properties of culinarymedicinal mushrooms. J. Inter. Med. Mushrooms 7: 103-110.

[29] Stott K, Caroline M (2004). Specialty MushroomProduction Systems: Maitake and Morels. RIRDC Publication. Kingston. pp: 1-95.

[30] Suzuki Y, Okano K, Kato S (1994). Characteristics of white rotted woody materials obtained from Shiitak mushroom(Lentinus edodes ad nameko mushrooom(Pholiota nameko) cultivation with in vitro rumen fermentation. J. Animal food sci.Tech.54: 227-236.

[31] Teklehaymanot T, Giday M (2010). Ethnobotanical study of wild edible plants of Kara and Kewego semipastoralist people in Lower Omo River valley, Debub Omo Zone, SNNPR, Ethiopia. J. Ethnobiol. Ethnomedicine 6: 23.

[32] Tuno N (2001). Mushroom utilization by the Majangir, an Ethiopian tribe. The Mycologist.15: 78- 79.

[33] Yildiz S, üCafer Derya-Gezer E, Temiz A (2002). Some lignocellulosic wastes used as raw material in cultivation of the Pleurotus ostreatus culture mushroom. Process Biochemistry 38: 301-306. 